\title{
Mathematical simulation of heat transfer at deciduous tree ignition by cloud-to-ground lightning discharge
}

\author{
Geniy V. Kuznetsov ${ }^{1}$, Nikolay V. Baranovskiy ${ }^{1}$ and Vladimir B. Barakhnin ${ }^{2,3}$ \\ ${ }^{1}$ National Research Tomsk Polytechnic University, Institute of Power Engineering, 634050 Tomsk, \\ Russia \\ ${ }^{2}$ Novosibirsk State University, High School of Informatics, 630090 Novosibirsk, Russia \\ ${ }^{3}$ Institute of Computational Technologies, Siberian Branch of Russian Academy of Science, \\ 630090 Novosibirsk, Russia
}

\begin{abstract}
Numerical research results of deciduous tree ignition by cloud-to-ground lightning discharge are presented. The problem is solved in one-dimensional statement in cylindrical system of coordinates. The typical range of influence parameters of positive and negative cloud-to-ground lightning discharges is considered. Ignition conditions for deciduous tree are established.
\end{abstract}

\section{Introduction}

Deterministic-probabilistic technique of the forest fires forecast taking into account storm activity [1-3] and system of the lightning caused fire danger forecast on satellite data TOVS [4] are developed by present time. Functionality of such systems can be considerably expanded by means of mathematical model of tree ignition by cloud-to-ground lightning discharge [5]. Various breeds of trees differ under many characteristics, including thermophysical and structural. It is known, that distinctions between coniferous and deciduous trees are most essential [6]. Therefore model [5] developed for coniferous trees cannot automatically be used for an estimation of ignition conditions of deciduous tree by cloudto-ground lightning discharge.

Research objective is creation of physical and mathematical model of deciduous tree ignition by the cloud-to-ground lightning discharge and definition of one ignition conditions.

\section{Physical and mathematical statement}

Electric current is course in deciduous and coniferous trees trunk variously [6]. It is caused by reason that moisture transport is carried out in a massive central pain trees of deciduous breeds [6]. More damp central part is an electric current conductor. The analysis of the known information on properties of wood of deciduous breeds shows, that it is necessary to consider moisture presence in structure of wood trunk for such trees. Moisture presence can essentially change conditions of ignition of wood even in

This is an Open Access article distributed under the terms of the Creative Commons Attribution License 4.0, which permits unrestricted use, distribution, and reproduction in any medium, provided the original work is properly cited. 


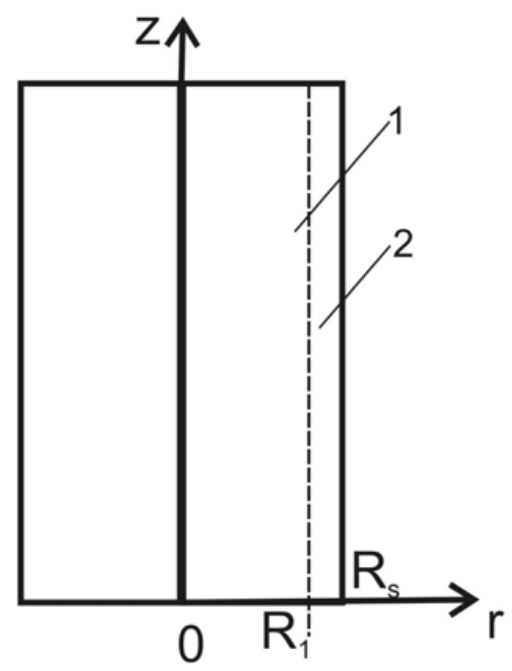

Figure 1. The scheme of decision area.

conditions of such rapid processes. Therefore at problem statement for trees of deciduous breeds it is expedient to consider influence of moisture on thermophysical wood characteristics.

The following physical model is considered. Cloud-to-ground lightning discharge strikes in tree trunk during the fixed moment of time. Electric current of cloud-to-ground lightning discharge proceeds on trunk. It is supposed, that in various sections of a trunk the electric current has identical parameters. It is supposed, that thermal emission occurs according Joule law. It is considered, that moisture evaporation can be described by equation of Knudsen-Lengmur [7]. There is a warming up of wood at the Joule heat production as a result of electric current course and achievement of critical thermal fluxes to ignition surface and one critical temperature. It is supposed, that formed porous space is filled with water vapor. Changes of volume fractions of phases are reflected on thermophysical properties of internal wood part of deciduous tree. Tree trunk is modelled by the cylinder. The representative section of a trunk is considered. The scheme of decision area is presented on Fig. 1.

Warming up of a tree trunk process before ignition by cloud-to-ground lightning discharge is described mathematically by system of the non-stationary differential equations:

$$
\begin{gathered}
\rho_{e f} \mathcal{c}_{e f} \frac{\partial T_{1}}{\partial t}=\frac{\lambda_{e f}}{r} \frac{\partial}{\partial r}\left(r \frac{\partial T_{1}}{\partial r}\right)+J U-Q W \varphi_{2}, \\
\rho_{2} c_{2} \frac{\partial T_{2}}{\partial t}=\frac{\lambda_{2}}{r} \frac{\partial}{\partial r}\left(r \frac{\partial T_{2}}{\partial r}\right), \\
\rho_{3} \frac{\partial \varphi_{1}}{\partial t}=0, \\
\rho_{4} \frac{\partial \varphi_{2}}{\partial t}=-W, \\
\sum_{i=3}^{5} \varphi_{i}=1,
\end{gathered}
$$




$$
\begin{gathered}
W=\frac{A\left(P^{s}-P\right)}{\sqrt{\frac{2 \pi R T}{M}}}, \\
\rho_{e f}=\rho_{3} \varphi_{3}+\rho_{4} \varphi_{4}+\rho_{5} \varphi_{5}, \quad c_{e f}=c_{3} \varphi_{3}+c_{4} \varphi_{4}+c_{5} \varphi_{5}, \quad \lambda_{e f}=\lambda_{3} \varphi_{3}+\lambda_{4} \varphi_{4}+\lambda_{5} \varphi_{5} .
\end{gathered}
$$

Boundary conditions for the Eqs. (1)-(2):

$$
\begin{gathered}
r=0, \quad \lambda_{e f} \frac{\partial T_{1}}{\partial r}=0, \\
r=R_{1}, \quad \lambda_{e f} \frac{\partial T_{1}}{\partial r}=\lambda_{2} \frac{\partial T_{2}}{\partial r}, T_{1}=T_{2} \\
r=R, \quad \lambda_{2} \frac{\partial T_{2}}{\partial r}=\alpha\left(T_{e}-T_{R s}\right) .
\end{gathered}
$$

Initial conditions for the Eqs. (1)-(5):

$$
t=0, \quad T_{i}(r)=T_{i 0}(r), \quad \varphi_{i}(0)=\varphi_{i 0} .
$$

Where $T_{i}$ - temperature of internal part of tree trunk (i=1) and bark (i=2); $\varphi_{i}$-volume fraction: organic substance $(\mathrm{i}=3)$, water $(\mathrm{i}=4)$ and water vapor $(\mathrm{i}=5) ; \rho_{\mathrm{i}}, c_{\mathrm{i}}, \lambda_{\mathrm{i}}$ - density, thermal capacity and heat conductivity of bark (i=2), organic substance $(i=3)$, water $(i=4)$ and water vapor $(i=5) ; \rho_{\text {ef }}, c_{\text {ef }}, \lambda_{\text {ef }}-$ effective density, thermal capacity and heat conductivity of internal part of wood trunk; $\alpha$ - heat transfer factor; $J$ - current; $U$ - voltage; $Q$ - thermal effect of moisture evaporation; $r$ - coordinate; $t$ - time. $W$ - mass speed of water evaporation, $A$ - accommodation factor, $\mathrm{P}^{\mathrm{s}}$ - pressure of sated water vapor, $P$ - partial pressure of water vapor in air, $R$ - universal gas constant, $M$ - molecular weight of water. Indexes " $R s$ ", " $e$ " and " 0 " correspond to parameters on external border of tree trunk, an environment and to parameters during initial moment of time.

Numerical research is spent with use of following initial data: $\rho_{3}=650 \mathrm{~kg} / \mathrm{m}^{3} ; c_{3}=$ $1670 \mathrm{~J} /(\mathrm{kg} \cdot \mathrm{K}) ; \lambda_{3}=0.29 \mathrm{~W} /(\mathrm{m} \cdot \mathrm{K}) ; \rho_{4}=1000 \mathrm{~kg} / \mathrm{m}^{3} ; c_{4}=4180 \mathrm{~J} /(\mathrm{kg} \cdot \mathrm{K}) ; \lambda_{4}=0.588 \mathrm{~W} /(\mathrm{m}$. $K) ; \rho_{5}=0.598 \mathrm{~kg} / \mathrm{m}^{3} ; c_{5}=2130 \mathrm{~J} /(\mathrm{kg} \cdot \mathrm{K}) ; \lambda_{5}=0.024 \mathrm{~W} /(\mathrm{m} \cdot \mathrm{K})$. Параметры испарения: $Q=2250 \mathrm{~J} / \mathrm{kg} ; A=0.1 ; R=8.31 \mathrm{~J} /($ mole $\cdot \mathrm{K}) ; \quad M=0.010 \mathrm{~kg} /$ mole. Parameters of external influence: $\alpha=80 \mathrm{~W} /\left(\mathrm{m}^{2} \cdot K\right)$.

\section{Results and discussion}

Formulated system of the Eqs. (1)-(5) with boundary and initial conditions (8)-(13) is solved by a method of finite differences [8]. The marching method in combination to method of simple iteration [8] was used for the decision of finite difference analogues of the one-dimensional equations.

Temperature and thermal flux (Table 1) are used as wood ignition criteria [9]. The following scenario of ignition was considered. The negative cloud-to-ground lightning discharge (duration $500 \mathrm{~ms}$, current $23.5 \mathrm{kA}$ and voltage $100 \mathrm{kV}$ ) influence on deciduous tree (birch). Temperature distribution on tree trunk radius to the various moments of time $(t=0.01 \mathrm{~s} ; 0.1 \mathrm{~s} ; 0.3 \mathrm{~s} ; 0.5 \mathrm{~s})$ before and at the ignition moment by an electric current (initial temperature $300 \mathrm{~K}$ ) presents on Fig. 2. Distribution of ignition surface temperature on time is resulted on Fig. 3a. Dependence of thermal flux to ignition surface on time is shown on Fig. 3b. There is an evaporation of moisture from deciduous tree wood eventually. All moisture evaporates approximately for half of time of influence of cloud-to-ground lightning discharge.

Parameters of the lightning discharge and ignition condition depending on voltage and obtained values are resulted in Table 2. Parameters of the lightning discharge and ignition condition depending on current are presented in Table 3. 
Table 1. Experimental data on conditions of birch wood ignition [9].

\begin{tabular}{|c|c|c|}
\hline Ignition delay time, $\mathrm{s}$ & Heat flux, $\mathrm{kW} / \mathrm{m}^{2}$ & Surface temperature, $\mathrm{K}$ \\
\hline 136 & 15 & - \\
\hline 61.2 & 21 & 645 \\
\hline 17.2 & 42 & 688 \\
\hline 1.8 & 125 & 755 \\
\hline 0.43 & 210 & 801 \\
\hline
\end{tabular}

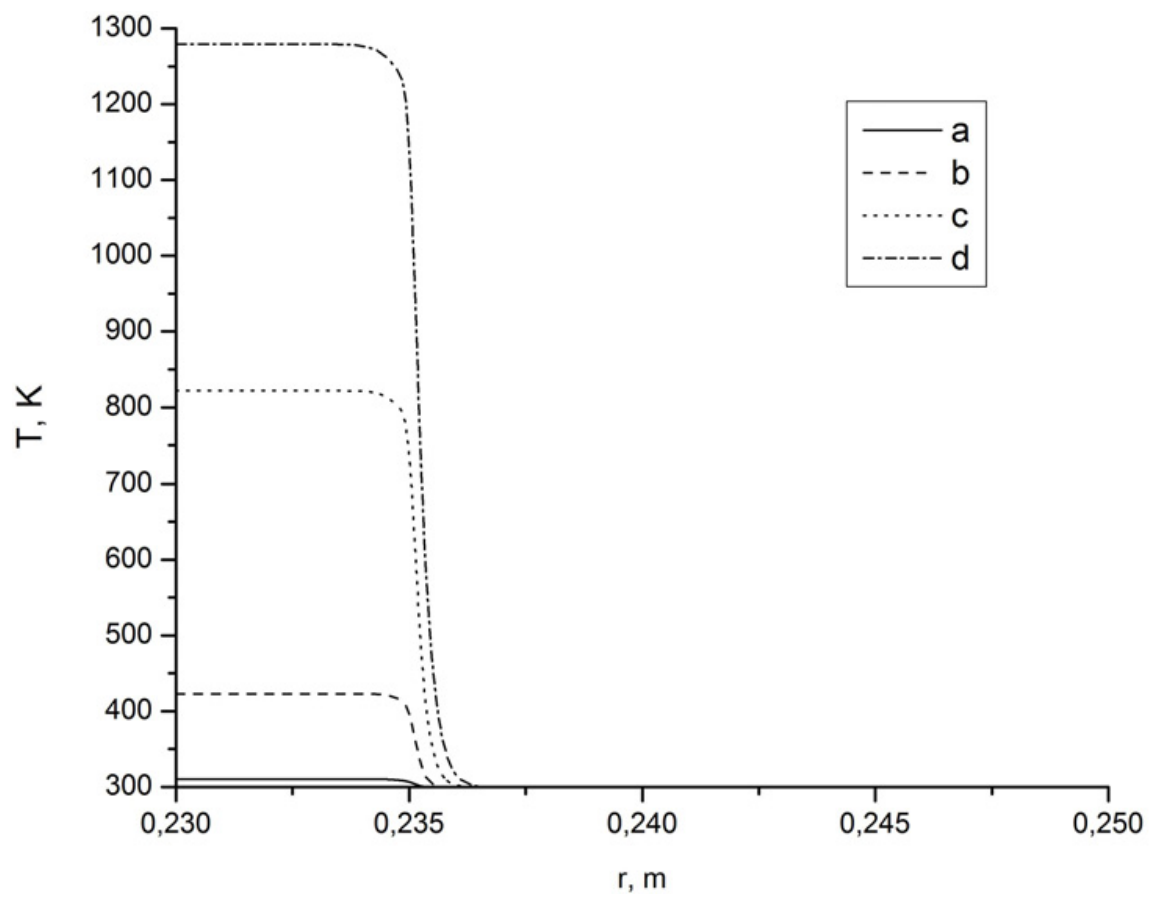

Figure 2. Temperature distribution on tree trunk radius during the various moments of time (duration of discharge action is $500 \mathrm{~ms}$ ): a) $\mathrm{t}=0.01 \mathrm{~s}$; b) $0.1 \mathrm{~s} ;$ c) $0.3 \mathrm{~s}$; d) $0.5 \mathrm{~s}$.
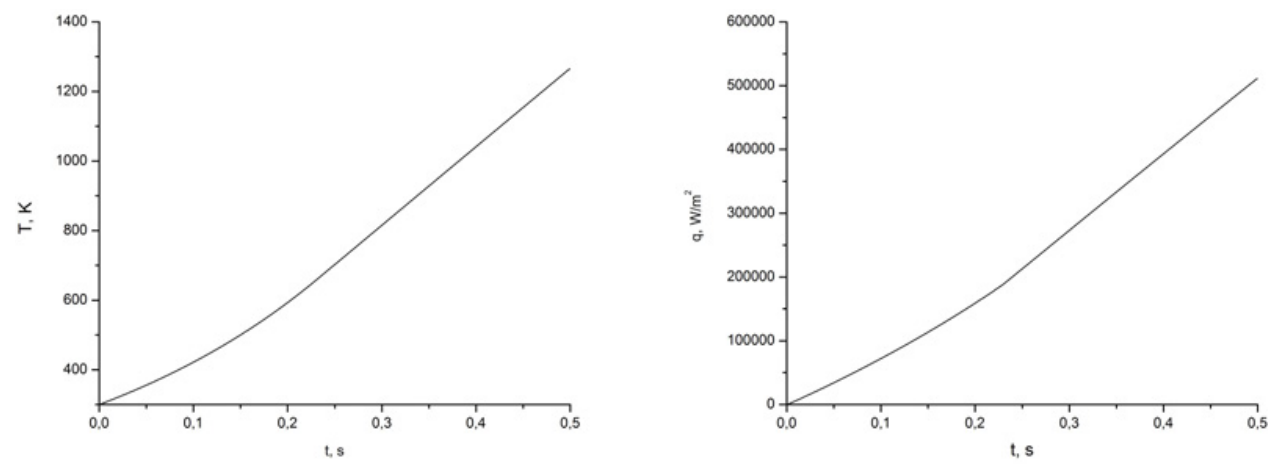

Figure 3. Temperature of subcrustal zone border of deciduous tree trunk (a) and thermal flux to ignition surface of tree trunk from subcrustal zone (b) during the various moments of time. 
Table 2. Ignition condition of tree depending on voltage of the discharge at current $\mathrm{J}=23.5 \mathrm{kA}$.

\begin{tabular}{|c|c|c|c|}
\hline Voltage, U, kV & Accordence to conditions [9] & Surface temperature, K & $\begin{array}{c}\text { Heat flux from subcrustal } \\
\text { zone to surface, } \mathrm{kW} / \mathrm{m}^{2}\end{array}$ \\
\hline $1-45$ & No & $<801$ & $<210$ \\
\hline 50 & & $<801$ & 252 \\
\hline 55 & Yes & 801 & 268 \\
\hline 60 & Yes & 801 & 268 \\
\hline 80 & Yes & 801 & 268 \\
\hline 100 & Yes & 801 & 268 \\
\hline 110 & Yes & 801 & 268 \\
\hline
\end{tabular}

Table 3. Ignition condition of tree trunk depending on current at voltage $\mathrm{U}=100 \mathrm{kV}$.

\begin{tabular}{|c|c|c|c|}
\hline Current, J, kA & Accordence to conditions [9] & Surface temperature, K & $\begin{array}{c}\text { Heat flux from subcrustal } \\
\text { zone to surface, } \mathrm{kW} / \mathrm{m}^{2}\end{array}$ \\
\hline $1-5$ & No & $<801$ & $<210$ \\
\cline { 3 - 4 } & & $<801$ & 214 \\
\hline 10 & Yes & 801 & 267 \\
\hline 15 & Yes & 801 & 268 \\
\hline 20 & Yes & 801 & 268 \\
\hline 23.5 & Yes & 801 & 268 \\
\hline 30 & Yes & 801 & 273 \\
\hline 35 & & & \\
\hline
\end{tabular}

The analysis of dependences presented on Fig. 2 shows, that tree trunk is warmed up to ignition temperature (more than $1000 \mathrm{~K}$ ) as result of action of considered cloud-to-ground lightning discharge. The analysis of results which are illustrated on Fig. 3 and Fig. 4, shows, that on critical temperature $(801 \mathrm{~K})$ and value of thermal flux $\left(268 \mathrm{~kW} / \mathrm{m}^{2}\right)$ [9] ignition conditions of deciduous tree are reached for a typical cloud-to-ground lightning discharge.

Ignition conditions of tree trunk during action of the electric discharge are established at various voltage (Table 2) and current (Table 3). There are no ignitions in action of cloud-to-ground lightning discharge (duration $500 \mathrm{~ms}$, current less than $15 \mathrm{kA}$ and voltage less than 1-50 kV) [10-13].

\section{Conclusion}

Possibility of deciduous tree ignition as a result of electric current course in trunk is shown as a result of the numerical decision of problem on ignition by the cloud-to-ground lightning discharge of deciduous tree containing moisture. The marked laws are characteristic for a typical range of parameters of external influence on wood of deciduous trees in storm conditions. The obtained results have not only the practical value consisting in a substantiation of a reality of the mechanism of deciduous tree ignition by cloud-to-ground lightning discharge. The established laws are also base for the further development of models of ignition of fire-dangerous materials and the theory of forest fires [14-17]. Existing techniques of the forest fire danger forecast can be added by forecast subsystems of deciduous trees ignition during storm weather conditions [18-20]. In particular, at creation of geoinformation systems of forest fire monitoring the analysis of satellite pictures allows to establish type of wood cover (coniferous or deciduous) on various sites of forest. That provides possibility of local application of corresponding ignition model by the cloud-to-ground lightning discharge. And considerably it allows to increasing forecast accuracy finally. 


\section{References}

[1] N.V. Baranovskiy, Matematicheskoe modelirovanie naibolee veroyatnikh scenariev $i$ usloviy vozniknoveniya lesnikh pozharov. Diss. ... Cand. fiz.-mat. nauk. (2007) (In Russian)

[2] N.V. Baranovskiy, Sibirskiy ecologicheskiy zhurnal, 6, 835 (2004) (In Russian)

[3] N.V. Baranovskiy, Ecologia i promyshlennost Rossii, 9, 59 (2008) (In Russian)

[4] E.I. Ponomarev E.I., V.A. Ivanov, Geographia i prirodnie resursi, 1, 147 (2006) (In Russian)

[5] G.V. Kuznetsov, N.V. Baranovskiy, EPJ Web of Conferences. 76, (01028), 1 (2014)

[6] K. Esau Anatomy of seed plants. (1977)

[7] A.V. Gusarov, I. Smurov, Physics of Fluid, 14, 4242 (2002)

[8] P. Majumdar, Computational Methods for Heat and Mass Transfer. (2005)

[9] A.E. Zabolotniy, M.M. Zabolotnaya, J.A. Zabolotnaya, V.N. Timoshin, Voprosy specialnogo mashinostroeniya, 7 - 8, 15 (1995) (In Russian)

[10] D. Latham, E. Williams, Forest fires: Behavior and Ecological Effects. (2001)

[11] C.P. Burke, D.L. Jones, Journal of Atmospheric and Solar-Terrestrial Physics, 58, 531 (1996)

[12] L.R. Soriano, F. De Pablo, C. Tomas, Journal of Atmospheric and Solar-Terrestrial Physics, 67, 1632 (2005)

[13] K.L. Cummins, M.J. Murphy, E.A. Bardo, W.L. Hiscox, R.B. Pyle, A.E. Pifer, Journal of Geophysical Research, 103, 9035 (1998)

[14] A.M. Grishin, N.V. Baranovskij, Journal of Engineering Physics and Thermophysics, 76, 166 (2003)

[15] N.V. Baranovskiy, M.V. Zharikova, Lecture Notes in Geoinformation and Cartography - LNG\&C. Thematic Cartography for the Society. 13 (2014)

[16] N.V. Baranovskiy, E.P. Yankovich, Proceedings of 5th International Conference on Cartography and GIS (Riviera, Bulgaria, 15 - 20 june 2014), 2, 756 (2014)

[17] E.P. Yankovich, N.V. Baranovskiy, $14^{\text {th }}$ International Multidisciplinary Scientific Geoconference SGEM - 2014. GeoConference on Informatics, Geoinformatics and Remote Sensing, 1, 607 (2014) (DOI: 10.5593/sgem2014B21)

[18] K.L. Pew, C.P.S. Larsen, Forest Ecology and Management, 140, 1 (2001)

[19] M. Conedera, G. Cesti, G.B. Pezzatti, T. Zumbrunnen, F. Spinedi, Forest Ecology and Management, 234, S68 (2006)

[20] F.G. Plummer, Bulletin 111. USDA Forest Service. (1912) 